\title{
PEMBUATAN SISTEM INFORMASI ALUMNI PADA TK ABA 16 MALANG MENGGUNAKAN BOOTSTRAP
}

\author{
Merinda Lestandy ${ }^{1}$, Achmad Nurdim Fikri², Adhi Nugraha ${ }^{3}$ \\ ${ }^{1)}$ Program Studi D3 Teknologi Elektronika, Fakultas Teknik, Universitas Muhammadiyah Malang \\ ${ }^{2)}$ Program Studi Teknik Elektro, Fakultas Teknik, Universitas Muhammadiyah Malang \\ ${ }^{3)}$ Program Studi Teknik Industri, Fakultas Teknik, Universitas Muhammadiyah Malang \\ e-mail: merindalestandy@umm.ac.id
}

\begin{abstract}
Abstrak
Salah satu upaya meningkatkan mutu sekolah yaitu dengan memanfaatkan teknologi informasi. Saat ini TK ABA 16 Malang belum memiliki sistem untuk menyimpan data siswa, alumni dan guru. Hal tersebut membuat TK ABA 16 Malang kesulitan ketika mencari data terkait siswa, alumni dan guru. Dari permasalahan mitra tersebut, dibuat Sistem Informasi Alumni TK ABA 16 Malang dengan menggunakan Bootstrap. Peserta yang menjadi mitra sasaran sebanyak 7 guru. Pengabdian ini dilakukan dengan 3 tahap yaitu, perancangan sistem dan model UML, implementasi sistem dan pelatihan sistem informasi. Hasil yang dicapai dalam kegiatan pengabdian masyarakat ini adalah pembuatan sistem informasi data alumni TK ABA 16 Malang dapat mengatasi masalah mitra sehingga lebih mudah dalam penyimpanan dan pencarian data siswa/alumni dan guru di dalam sistem.
\end{abstract}

Kata kunci: Sistem Informasi, Sekolah, Alumni

\begin{abstract}
One of the efforts to improve the quality of schools by utilizing information technology. Currently TK ABA 16 Malang does not have a system to store student, alumni and teacher data. This makes TK ABA 16 Malang difficult when looking for data related to students, alumni and teachers. From the partners' problems, an Information System for TK ABA 16 Malang Alumni was created using Bootstrap. Participants who became target partners were 7 teachers. This service is carried out in 3 stages, namely, system design and UML model, system implementation and information system training. The results achieved in this community service activity is the creation of a data information system for TK ABA 16 Malang alumni that can solve partner problems so that it is easier to store and search student /alumni and teacher data in the system.
\end{abstract}

Keywords: Information Systems, School, Alumni

\section{PENDAHULUAN}

Pesatnya perkembangan ilmu pengetahuan dan teknologi pada saat ini tidak dapat dipungkiri lagi. Kebutuhan yang mendesak dan semakin berharganya nilai waktu membuat banyak orang bekerja dengan cepat dan efektif sehingga mendapatkan hasil yang maksimal (Ramadhani et al., 2013). Aplikasi komputer merupakan sebuah sistem pengolah data menjadi sebuah informasi yang berkualitas dan dipergunakan untuk suatu alat bantu pengambil keputusan (Wamiliana et al., 2014).

Teknologi informasi dan komunikasi melahirkan berbagai media yang mampu memberikan informasi yang dapat diakses kapanpun dan dimanapun yaitu website. Website menjadi salah satu media yang sering dimanfaatkan oleh manusia baik untuk kepentingan pribadi maupun kepentingan institusi (Christian et al., 2018). Dalam dunia pendidikan informasi adalah bagian penting dari komponen pendidikan yang dituntut untuk didapatkan secara cepat, tepat dan mudah agar mendukung segala bentuk kegiatan pendidikan yang sedang dan akan berlangsung di instansiinstansi tertentu.

Pendidikan mempunyai peranan yang amat strategis untuk mempersiapkan generasi muda yang memiliki keberdayaan dan kecerdasan emosional yang tinggi dan menguasai megaskills yang mantap. Sejarah telah membuktikan bahwa kemajuan dan kejayaan suatu bangsa di dunia ditentukan oleh kualitas dan mutu dibidang pendidikan (Fauzi, 2019). Sekolah merupakan lembaga 
diberi wewenang untuk menyelenggarakan kegiatan belajar dan mengajar antara siswa dan guru. Sampai dengan saat ini sekolah masih diberikan kepercayaan oleh sebagian besar masyarakat untuk menjadi tempat bagi siswa untuk menuntut ilmu dan sebagai tempat proses mendewasakan anak-anak (Irawan et al., 2016).

TK ABA 16 berdiri secara resmi pada tanggal 1 Januari 1971. Awalnya TK ABA 16 merupakan kepemilikan pribadi salah seorang tokoh Muhammadiyah Ranting Dinoyo yaitu $\mathrm{Hj}$. Fathkhurozi yang berlokasi di Jl. MT haryono Gang II No 517 Kota Malang. Kemudian TK ABA 16 diwaqafkan kepada kepemimpinan Aisyiyah yaitu Ibu Abdullah Hasyim. Beliau menjabat sebagai ketua Aisyiyah Ranting Dinoyo selama 1 periode (5 tahun). Kemudian pada periode ke 2 dijabat oleh Hj. Ikhsan sampai tahun 1984. Kepemimpinan TK ABA 16 Ranting Dinoyo periode ke 3 dijabat kembali oleh Abdullah Hasyim, setelah itu TK ABA 16 dipindahkan dan dibangun di Jl. Watu Gilang no. 43 Kota Malang. Kemudian pada tahun 2000, periode ke 4 dipimpin oleh Dra. Nurliani sampai tahun 2005. Periode ke 5 dipimpin oleh Asminingtyas, S.Pd sampai tahun 2010. Pada periode ke 6 dipimpin oleh $\mathrm{Hj}$. Dra. Dwi Widariyati hingga sekarang. Nama TK ABA 16 merupakan TK dengan urutan ke 16 dari 34 TK ABA Se Kota Malang, dan yang bertanggung jawab atas TK ABA 16 adalah Pimpinan Aisyiyah Ranting Dinoyo.

Pada TK ABA 16 Malang terdapat 2 kelas, kelas A dan kelas B dengan jumlah keseluruhan sebanyak 80 murid. Banyaknya murid laki-laki pada kelas A yaitu 18 dan perempuan sebanyak 21. Sedangkan pada kelas B, jumlah murid laki-laki sebesar 17 dan jumlah murid perempuan sebesar 45. Guru yang mengajar pada TK ABA sebanyak 7 orang.

Berdasarkan hasil diskusi tim pengusul dengan mitra, permasalahan TK ABA 16 Malang saat ini belum memiliki sistem untuk menyimpan data siswa, alumni dan guru. Hal tersebut membuat TK ABA 16 Malang kesulitan ketika mencari data terkait siswa, alumni dan guru. Berdasarkan analisa situasi yang kami lakukan, kami sepakat bersama mitra bahwa dalam pengabdian oleh tim tahun ini adalah kegiatan masyarakat dengan membuat aplikasi sistem informasi TK ABA 16 Malang dengan tujuan agar dapat memudahkan guru dalam mencari data sekolah dan dapat meningkatkan mutu sekolah.

\section{METODE}

A. Perancangan Sistem

Pada tahap perancangan sistem yang akan dilakukan untuk mendesain aplikasi Sistem Informasi Data Alumni pada TK 'Aisyiyah Bustanul Afthal 16 Malang. Gambaran diagram blok dari aplikasi ini dapat dilihat pada gambar dibawah ini.

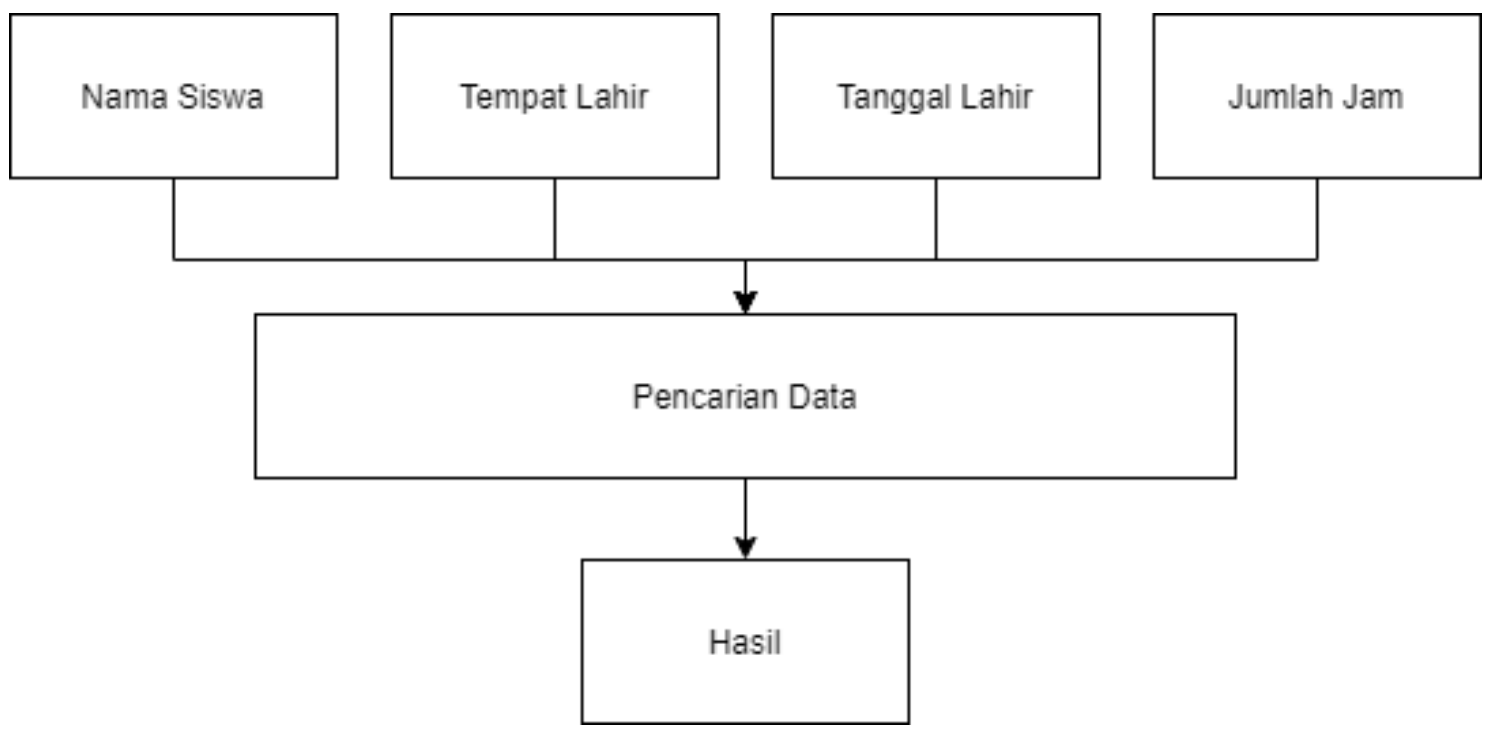

Gambar 1. Diagram Blok Guru 


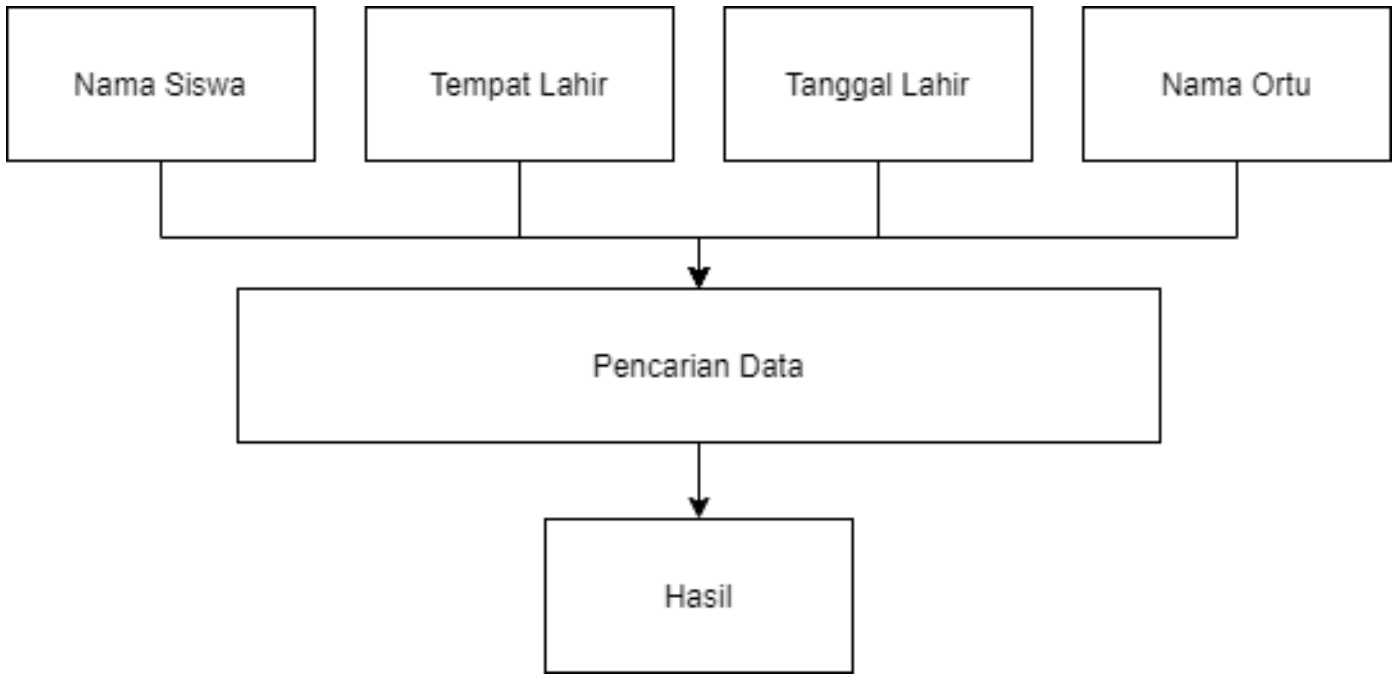

Gambar 2. Diagram Blok Siswa

B. Perancangan Model Menggunakan UML

1. Usecase Diagram

Seorang guru/admin bisa melakukan login dengan input data (register) terlebih dahulu. Selain itu admin juga bisa melihat data guru dan mahasiswa. Usecase admin/guru dari aplikasi yang akan dirancang pada penelitian ini dapat dilihat pada Gambar 3.

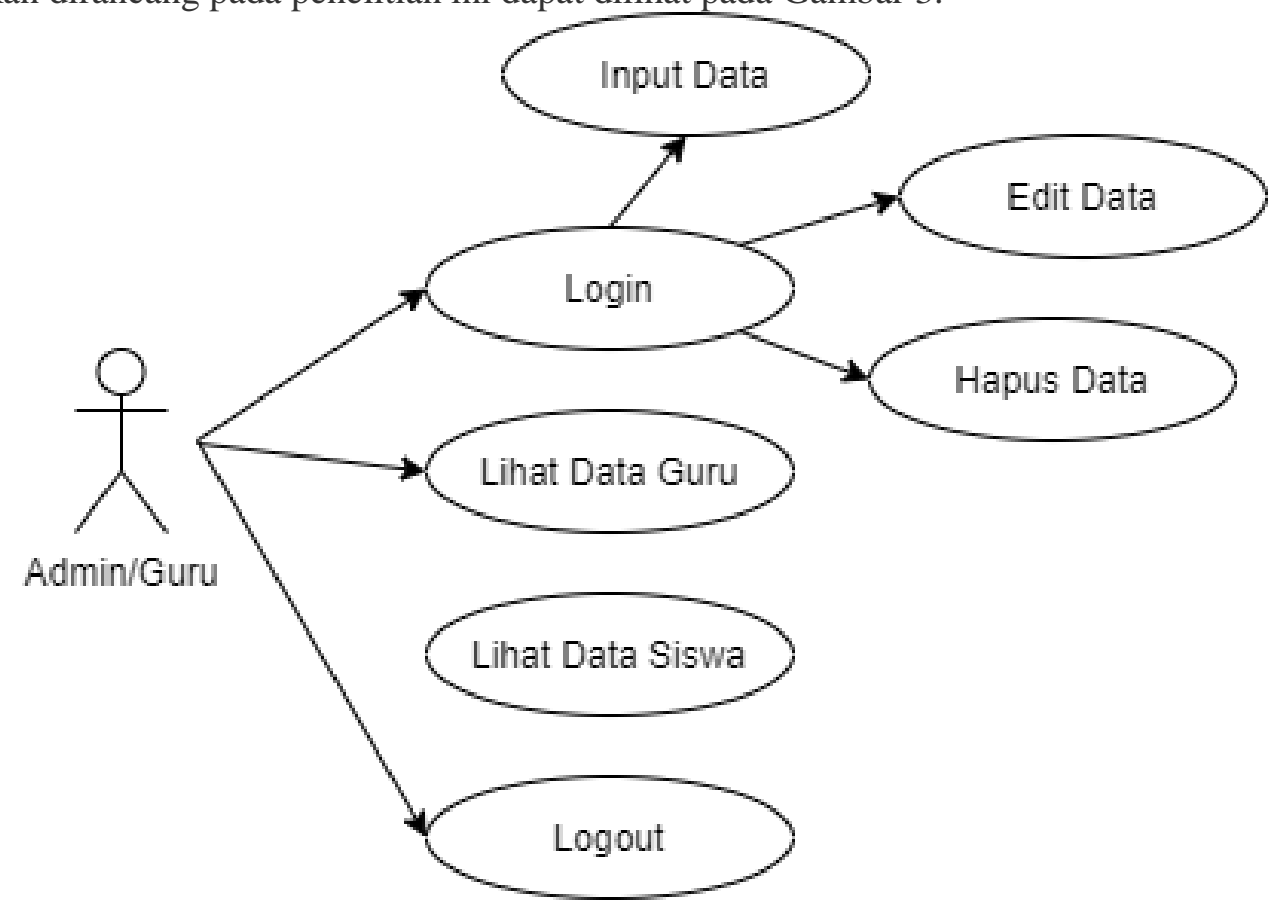

Gambar 3. Usecase Admin/Guru

2. Entity Relationship Diagram (ERD)

Perancangan database pada penelitian ini terdiri dari 2 tabel yaitu tabel siswa dan tabel guru. Variabel pada tabel siswa antara lain nama siswa, tempat lahir, tanggal lahir, nama orang tua dan alamat. Sedangkan variabel pada tabel guru yaitu nama guru, NUPTK, gol/ruang, jabatan, tugas mengajar, jumlah jam, kelas dan jam.

Pada Gambar 4. dibawah ini merupakan gambaran perancangan dari database yang menggunakan beberapa notasi untuk menggabarkan data sebagai penganti istilah entitas relasinya. 


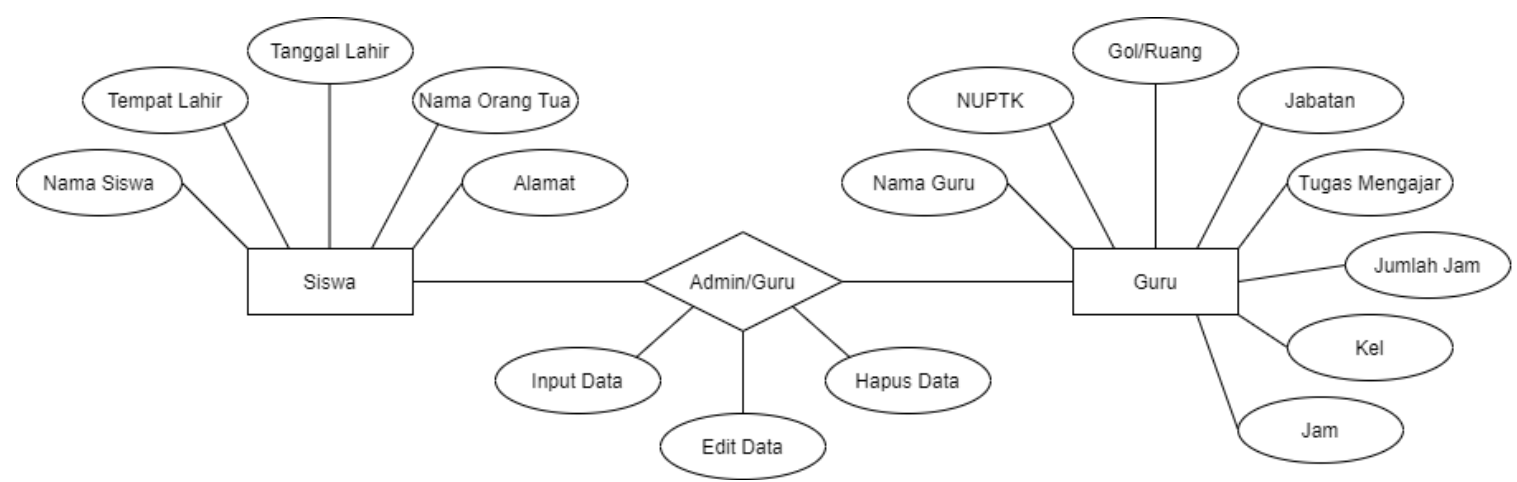

Gambar 4. ERD Sistem

3. Flowchart

Flowchart aplikasi ini dapat dilihat pada Gambar 5.

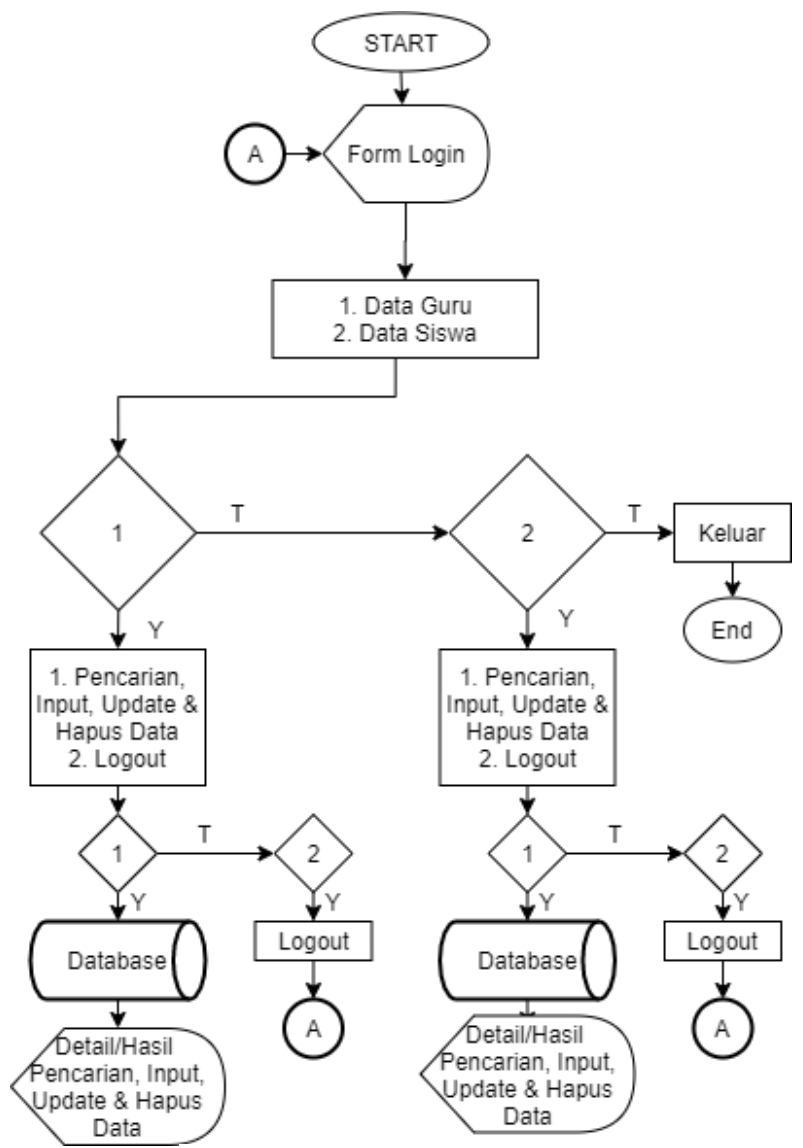

Gambar 5. Flowchart Sistem

Metode : menguraikan cara yang digunakan untuk menyelesaikan masalah. Contoh metode : a) Pendidikan Masyarakat, misalnya penyuluhan yang bertujuan meningkatkan pemahaman serta kesadaran, b) Difusi Ipteks, misalnya kegiatan yang menghasilkan produk bagi kelompok sasaran, c) Pelatihan, misalnya kegiatan yang disertai dengan demonstrasi atau percontohan untuk menghasilkan keterampilan tertentu, d) Mediasi, misalnya kegiatan yang menunjukkan pelaksana PkM sebagai mediator dalam menyelesaikan masalah yang ada dalam masyarakat, e) Advokasi, misalnya kegiatan yang berupa pendampingan terhadap kelompok sasaran 


\section{HASIL DAN PEMBAHASAN}

A. Implementasi Aplikasi

Implementasi aplikasi merupakan proses mengubah system yang telah dirancang dan didesain kemudian diterapkan dalam program.

1. Proses Login

User harus melakukan login Ketika akan masuk aplikasi dengan memasukkan username dan login terlebih dahulu. Tampilan menu Login dapat dilihat pada Gambar 6. dibawah ini.

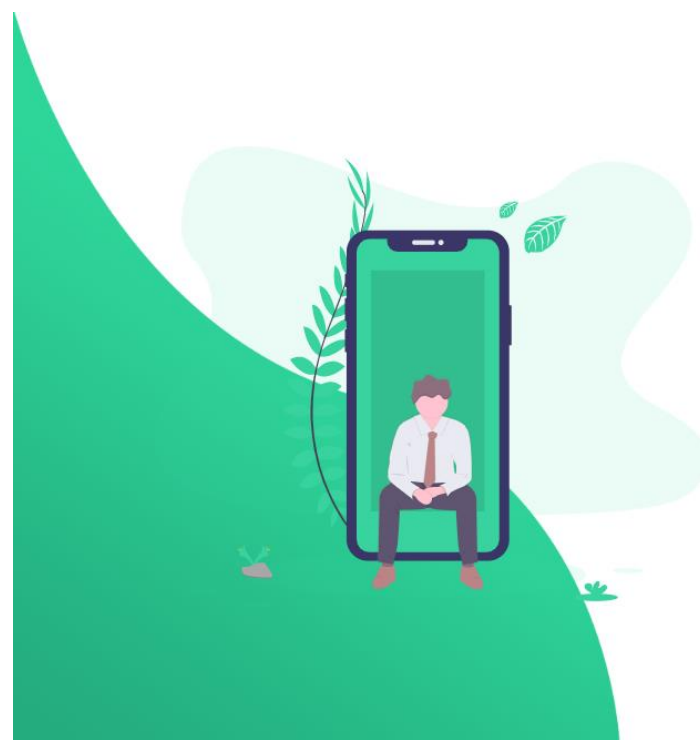

\section{素此产}

\section{WELCOME}

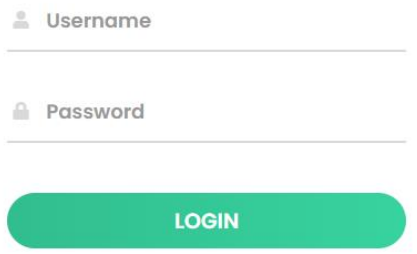

Gambar 6. Tampilan Login Page

2. Halaman Menu Dashboard Admin/Guru

Halaman menu dashboard admin/guru ini menampilkan seluruh table dari aplikasi ini dimana admin dapat mengakses masing-masing tabel dan melakukan aksi pencarian, menambahkan, menghapus dan juga mengimport data.

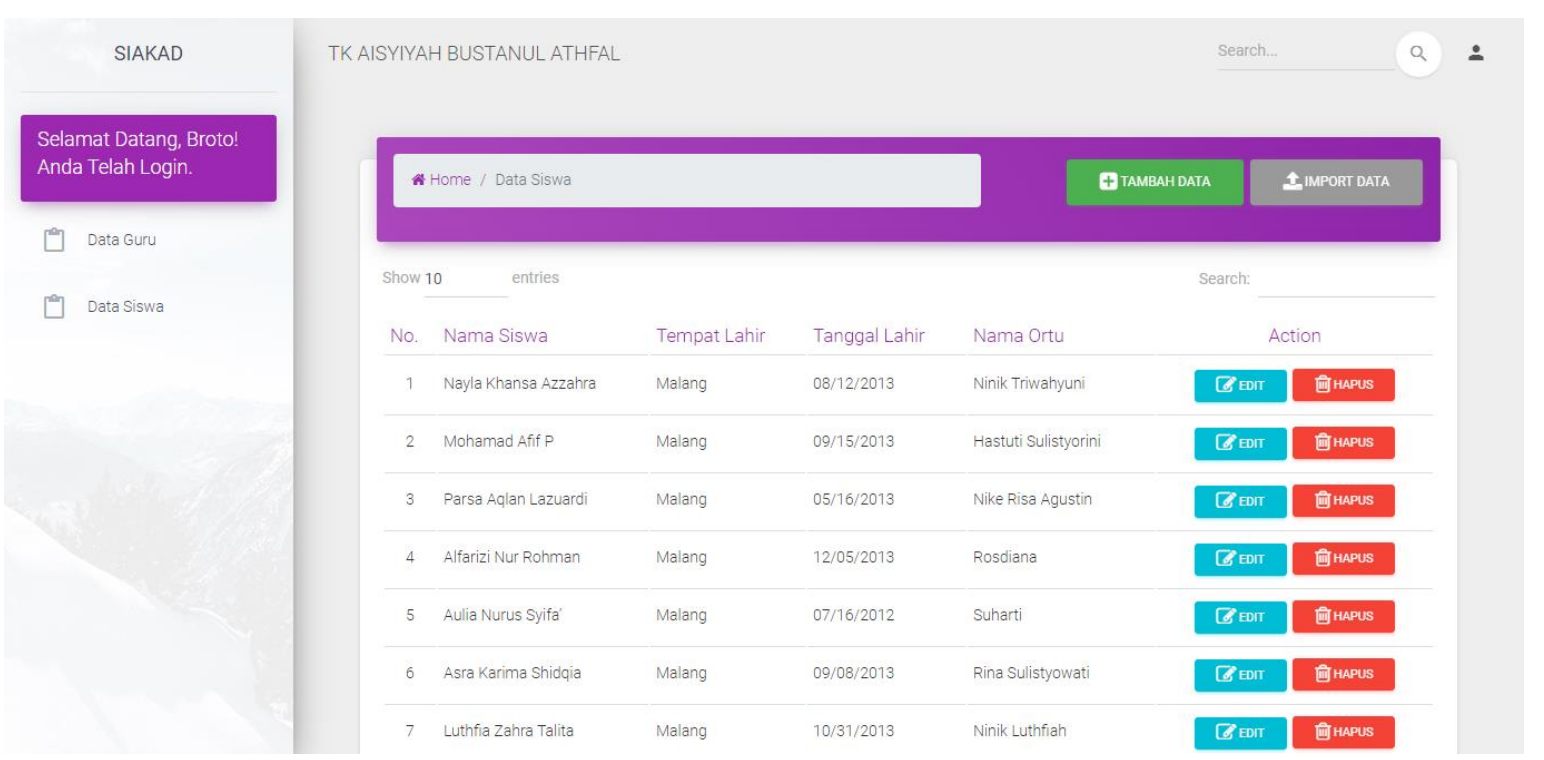

Gambar 7. Tampilan Halaman Siswa pada Dashboard Admin 


\begin{tabular}{|ll|}
\hline Tambah Data & \\
Nama Siswa & $\begin{array}{l}\text { Tanggal Lahir } \\
\text { DD/MM/YY }\end{array}$ \\
\hline Nempat Lahir & \\
\hline Alamat & \\
\hline Rang Tua & \\
\hline
\end{tabular}

Gambar 8. Tampilan Tambah Data Siswa

\begin{tabular}{|ll|}
\hline Edit Data & \\
Nama Siswa & \\
Nayla Khansa Azzahra & Tanggal Lahir \\
\hline Tempat Lahir & $08 / 12 / 2013$ \\
\hline Malang & \\
\hline Nama Orang Tua & \\
\hline Ninik Triwahyuni & \\
\hline Alamat Watu Gilang 18 B & \\
\hline & \\
\hline
\end{tabular}

Gambar 9. Tampilah Edit Data Siswa

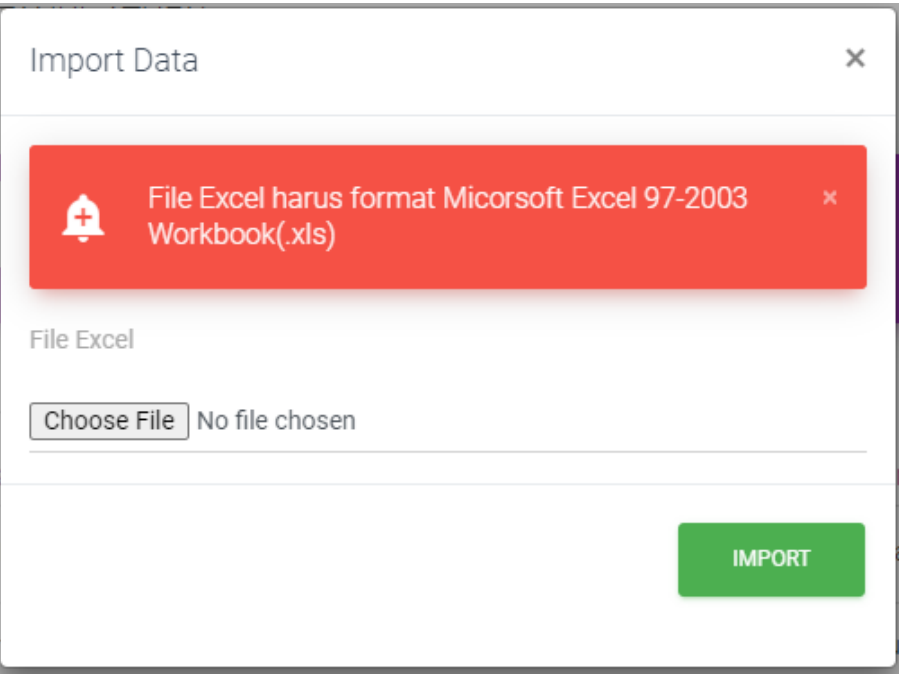

Gambar 10. Tampilan Import Data Sistem 


\section{B. Pengujian Fungsional/Black Box Testing}

Pengujian merupakan hal penting dalam merancang apikasi yang bertujuan agar mendapatkan hasil aplikasi yang berjalan tanpa kendala dan dapat berfungsi sesuai dengan perancangan sistem. Pengujian ini dilakukan untuk menguji dan memastikan bahwa semua fungsifungsi khusus dari aplikasi yang sudah dirancang telah terpenuhi dalam sistem aplikasi. Pengujian fungsional aplikasi dapat dilihat pada Tabel 1.

Tabel 1. Pengujian Fungsional

\begin{tabular}{cccc}
\hline Fitur & Cara Kerja & Keterangan & Referensi Gambar \\
\hline Login & Input username dan password & Berhasil & Gambar 6 \\
\hline Input & Memasukkan seluruh data alumni dengan & Berhasil & Gambar 8 \\
Data & menekan tombol Tambah Data pada bagian & & \\
(Guru & bawah tabel & & \\
dan & & & \\
Siswa) & Mengubah beberapa data alumni dengan & Berhasil & Gambar 9 \\
\hline Edit Data & menekan tombol Edit pada kolom Action & & \\
(Guru & & & Gambar 10 \\
dan & & Berhasil & \\
Siswa) & Mengupload data excel alumni dengan format & & \\
\hline Import & Matan & & \\
Data & (.xls) sesuai dengan template database dengan & & \\
(Guru & menekan tombol Import Data pada bagian & & \\
dan & bawah tabel & & \\
Siswa) & & & \\
\hline
\end{tabular}

C. Pelaksanaan Pelatihan

Pelaksanan pelatihan Sistem Informasi Alumni pada TK ABA 16 Malang dilaksanakan pada 4 September 2020 dan berlangsung di Aula TK seperti yang terlihat pada Gambar 11 dan Gambar 12. Dalam pelaksanaannya, pemateri menyajikan beberapa materi yang memberikan pemahaman dan langkah-langkah mengenai sistem informasi yang telah dibuat kepada guru-guru. Pelatihan yang diberikan mendapat respons yang positif dari peserta. Kepala Sekolah TK ABA 16 Malang, Ibu Ifa Irawati, S.Pd., berharap ada tindak lanjut setelah pelatihan yang dilaksanakan dan sistem informasi yang telah dibuat karena sekolah memerlukan hal-hal seperti ini untuk meningkatkan mutu sekolah.

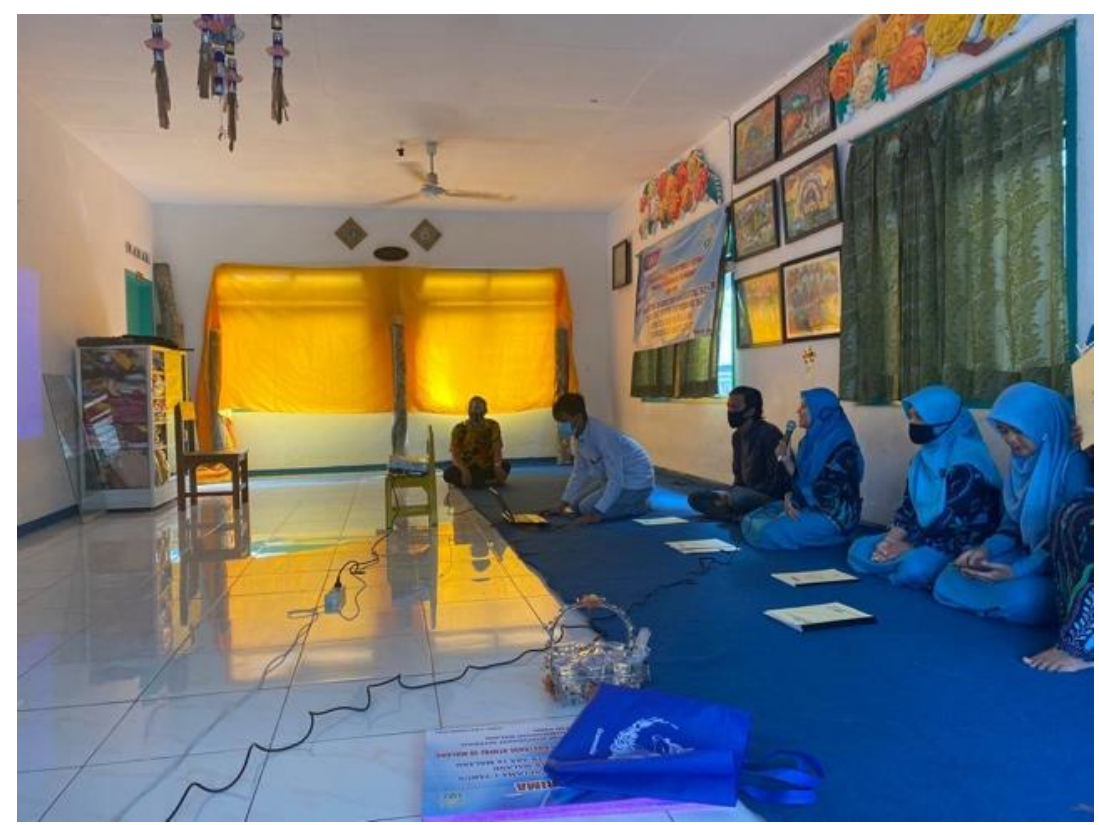

Gambar 11. Pemaparan Materi 


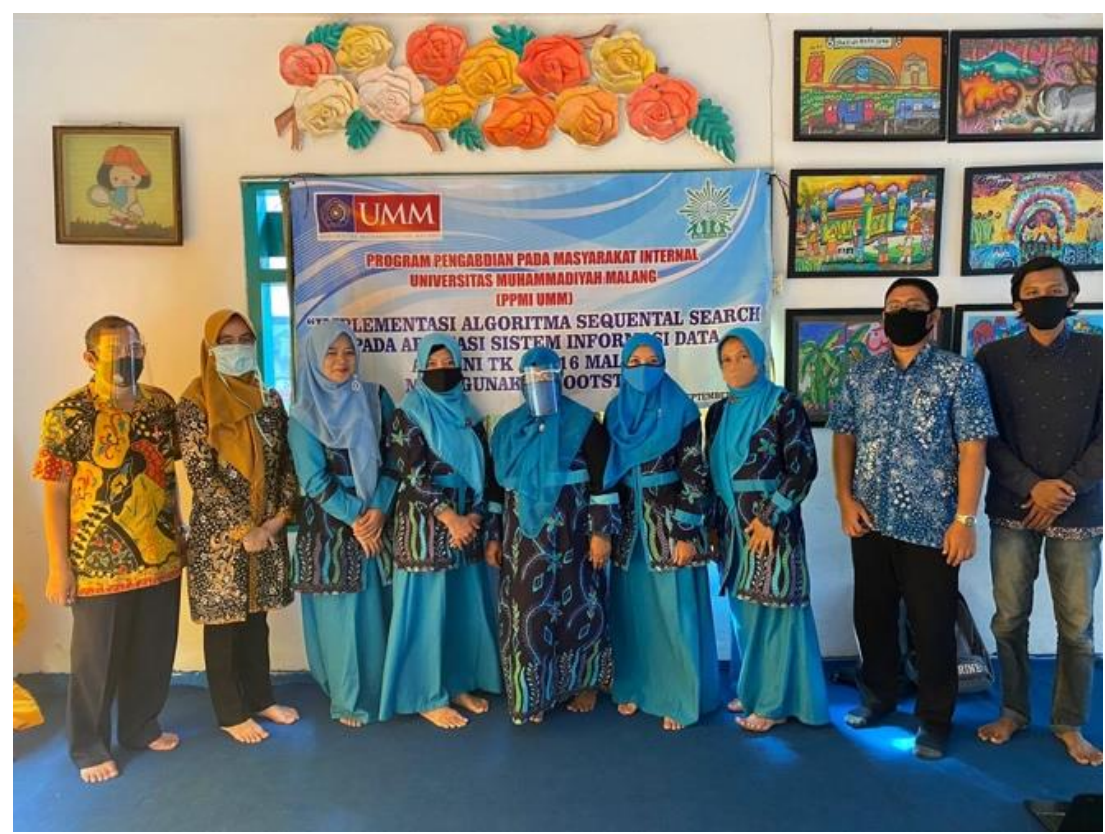

\section{SIMPULAN}

Gambar 12. Foto Bersama Guru TK ABA 16 Malang

Berdasarkan pembahasan diatas, kegiatan pengabdian masyarakat ini mampu menyelesaikan masalah mitra yang belum memiliki fasilitas aplikasi sistem informasi data alumni/guru dimana penyimpanan datanya selama ini masih manual. Hasil yang dicapai dalam kegiatan pengabdian masyarakat ini adalah pembuatan aplikasi sistem informasi data alumni TK ABA 16 Malang dapat mengatasi masalah mitra sehingga lebih mudah dalam penyimpanan dan pencarian data siswa/alumni dan guru di dalam sistem.

\section{SARAN}

Dari kegiatan pengabdian ini, tim penulis menyarankan para guru TK ABA 16 Malang untuk tetap melakukan update dan maintenance aplikasi sesuai dengan perubahan kondisi sekolah.

\section{UCAPAN TERIMA KASIH}

Terima kasih kepada Direktorat Penelitian dan Pengabdian kepada Masyarakat (DPPM) Universitas Muhammadiyah Malang atas dukungan terselenggaranya pekerjaan ini melalui skema Program Pengabdian Masyarakat Internal (PPMI) 2020.

\section{DAFTAR PUSTAKA}

Christian, A., Hesinto, S., \& Agustina, A. (2018). Rancang Bangun Website Sekolah Dengan Menggunakan Framework Bootstrap ( Studi Kasus SMP Negeri 6 Prabumulih ). Jurnal $\begin{array}{llllll}\text { Sisfokom (Sistem Informasi Dan } & \text { Komputer), } & 7(1), & 22 .\end{array}$ https://doi.org/10.32736/sisfokom.v7i1.278

Fauzi, F. (2019). Implementasi Manajemen Berbasis Sekolah (MBS) dalam Peningkatan Prestasi Belajar Siswa di SMP 10 Nopember Sidoarjo. Jurnal Tarbawi STAI Al Fithrah, 61-76.

Irawan, Y., Susanti, N., \& Triyanto, W. A. (2016). Analisa Dan Perancangan Sistem Informasi Sekolah Berbasis Website Untuk Penyampaian Informasi Sekolah Dan Media Promosi Kepada Masyarakat. Simetris : Jurnal Teknik Mesin, Elektro Dan Ilmu Komputer, 7(1), 257. https://doi.org/10.24176/simet.v7i1.512

Ramadhani, S., Anis, U., \& Masmuro, S. T. (2013). Rancang Bangun Sistem Informasi Geografis Layanan Kesehatan Di Kecamatan Lamongan Dengan PHP MySQL. Jurnal Teknika, 5(MYsql), 479-484. https://doi.org/10.1007/978-1-62703-471-5_1

Wamiliana, Wardhana, W., \& Hardiyanti, A. (2014). Penerapan Algoritma Sequential Search dalam Proses Pencarian Informasi pada Sistem Pembelajaran Organ Jantung Manusia. Jurnal Komputasi, 2(2), 115-125. 